\title{
Brunner's Gland Hyperplasia
}

National Cancer Institute

\section{Source}

National Cancer Institute. Brunner's Gland Hyperplasia. NCI Thesaurus. Code C135565.

A rare hyperplastic lesion of Brunner's gland in the duodenum. Although it is usually asymptomatic and discovered incidentally during upper gastrointestinal endoscopy, it may cause hemorrhage. 